\title{
ОСОБЕННОСТИ \\ СОЦИАЛЬНО-ФИЛОСОФСКОЙ РЕФЛЕКСИИ ФЕНОМЕНА ТЕХНОЛОГИИ В УСЛОВИЯХ ИНФОРМАТИЗАЦИИ ПОСТИНДУСТРИАЛЬНОГО ОБЩЕСТВА
}

\section{Пелевин С.И.}

Цель. Актуальность сочииально-философского анализа и рефлексии технологии как феномена сочиальной реальности приобретает особую значимость в современном мире в условиях глобальной пандемии, которая вывела информатизацию постиндустриального общества на качественно новый уровень. В статье постиндустриальное общество рассматривается также как общество постмодерна, в котором на смену цеентрации и тотальности классического индустриального Модерна приходят децентращия и фрагментация. Кроме того, в работе указано, что, в постиндустриальном обществе под каталитическим воздействием процессов информатизаичии особую значимость приобретают постматериальные изенности, то есть экологические императивы, иченности социального государства, и гражданских свобод.

Задачи. Рассмотреть развитие постиндустриального общества в контексте техногенного прорыва и обобщить уже имеющийся научный опыт по данной проблематике.

Методы. В результате применения вышеуказанных теорий и концептуальных схем в фокус исследовательского интереса вместе с процессами информатизации попадают сопутствующие процессы цุифровизации и медиатизации общзества и социальных структур.

Результаты. Сделан вывод о том, что в постиндустриальном обществе технологический прорыв, связанный с процессами информатизации и циирровизации, приводит к появлению новых рисков для сочиальных субъектов. 
Область применения результатов. Результаты исследования негативных и позитивных тенденщий и сопутствующих рисков прочессов информатизации в современных условиях глобализации и ичифровизации жизнедеятельности индивидов с учетом контроля за их деятельностью со стороны социальных структур могут быть применены различными сочиальными структурами с целью обобщения и уточнения информаџии, особенно в условиях посткарантинного мира.

Ключевые слова: технология; классический Модерн; индустриализм; постиндустриализм; ситуация постмодерна; общество знаний; информационное общество.

\section{PECULIARITIES OF SOCIA L-PHILOSOPHICAL REFLECTION OF THE PHENOMENON OF TECHNOLOGY IN THE CONDITIONS OF INFORMATIZATION OF A POST-INDUSTRIAL SOCIETY}

\section{Pelevin S.I.}

Purpose. The relevance of considering and socio-philosophical analysis and reflection of technology as a phenomenon of social reality is of particular importance in the modern world in the context of a global pandemic, which brought the informatization of post-industrial society to a whole new level. In the article, a post-industrial society is also considered as a postmodern society, in which decentration and fragmentation come to replace the center and totality of the classical industrial Modern. In addition, the work indicates that, in a post-industrial society, under the catalytic influence of informatization processes, post-material values, that is, environmental imperatives and the values of the social state and civil liberties, are of particular importance.

Tasks. To consider the development of post-industrial society in the context of technological breakthrough and to summarize the existing scientific experience on this issue. 
Methodology. As a result of applying the above theories and conceptual schemes, the accompanying processes of digitalization and mediatization of society and social structures fall into the focus of research interest along with the processes of informatization.

Results. It is concluded that in a post-industrial society a technological breakthrough associated with the processes of informatization and digitalization leads to new risks for social actors.

Practical implications. The results of the study of negative and positive trends and associated risks of informatization processes in modern conditions of globalization and digitalization of the life of individuals, taking into account the control of their activities by social structures, can be applied by various social structures in order to generalize and refine information, especially in the post-quarantine world.

Keywords: technology; classic modern; industrialism; post-industrialism; postmodern situation; knowledge society; information society.

Особую роль в постмодернистском обществе играет процесс медиатизации, являющийся, по сути дела, процессом генетически связанным с информатизацией [3]. Медиатизация должна рассматриваться как двусторонний процесс. С одной стороны, средства массовой информации, становятся независимым институтом с собственной логикой, которой должны соответствовать другие социальные институты. С другой стороны, одновременно СМИ становятся неотъемлемой частью других институтов, таких как политика, работа, семья и религия, поскольку все больше институциональных мероприятий осуществляется как через интерактивные, так и через средства массовой информации [4]. Логика средств массовой информации относится к институциональным и технологическим способам работы средств массовой информации, включая способы, которыми средства массовой информации распространяют материальные и символические ресурсы и используют формальные и неформальные правила, все больше применяя информационные технологии [7].

Важным является то, что в обществе постиндустриальном, постмодернистском, согласно концепции постматериализма Рональ- 
да Инглхарта, разработанная в труде «Молчаливая революция: изменение системы ценностей и политического стиля в западном обществе» [9], превалируют не материальные, а разнообразные постматериальные ценности, что существенно усложняет ориентиры жизнедеятельности социальных субъектов, институциональную структуру общества и расширяет поля социальных практик, диверсифицирую их.

Информационные процессы являются своеобразными катализаторами усиления значимости постматериальных ценностей в глобальном мире и локальных сообществах. При этом под постматериальными ценностями понимаются ценности социального государства и гражданских свобод, а также экологические императивы как антитезы ценностям материального потребления классического капитализма [5].

В противовес экономике классического Модерна, информационная экономика как экономика эпохи постиндустриализма более разнообразна и ориентирована не только на производство материальных вещей, но и на производство в социокультурной среде продуктов и смыслов. Именно Интернет как информационная среда постиндустриального общества способствует интенсивному и ускоренному переносу культурных продуктов из социокультурной сферы к индивидам как социальным субъектам [11]. И именно Интернет расширяет возможности удовлетворения разнообразных потребностей индивидов благодаря расширению системы торговли товарами через сети и системы транспортировки продуктов индивидуальным потребителям.

В итоге, в современном обществе на одном полюсе информационной экономики находятся транснациональные корпорации, нацеленные в своей работе на унифицированные потребности индивидов. Но другом полюсе информационной экономики существуют и функционируют небольшие предприятия и фирмы, ориентированные на создание индивидуализированных продуктов.

В постиндустриальном обществе поддержание устойчивости и целостности институционально-социальной системы, ее развитие на фоне растущей индивидуализации социальных субъектов и со- 
циокультурной фрагментации и децентрации фактически были бы невозможны без устойчивости расширяющихся информационных потоков и активного использования современных средств коммуникации. В свою очередь, в экономической сфере создание индивидуализированных продуктов было бы невозможно без сбора, обработки и распределения информации среди этих производителей.

Заметим, что если в обществе классического индустриального Модерна реклама была ориентирована на усредненного, «модального» потребителя, то в современном информационном обществе, постиндустриальном по своему характеру, реклама ориентирована на индивидуального потребителя. Происходит это благодаря информационным технологиям (например, технологиям сбора cookie-файлов и web-маяков для поддержания работы web-сайтов сбора статистики).

Использование термина «информационное общество» для описания современного постиндустриализма отражает ряд технологических реалий современности.

Во-первых, в обществе осуществляется полноценный переход от использования дискретных механических устройств, электрических приборов и электромеханических агрегатов к целостным информатизированным электронным системам. Так, например, в нефтегазовой промышленности управление добычей лет пятьдесят назад осуществлялось на основе использования аналоговых электрических схем, тогда как в наши дни в высокотехнологических компаниях оно максимальным образом информатизировано и компьютеризировано.

Во-вторых, развитие технологий привело к микроминимизации элементной базы электронной техники, а, вслед за этим и устройств, сконструированных и созданных на их основе.

Третьим трендом развития информационного общества является цифровизация (дигитализация) коммуникации и информации. Цифровизация стала краеугольным камнем конкурентоспособности на промышленной арене, особенно в случаях небольших партий с большим количеством вариантов выпускаемой продукции. Менеджеры промышленных предприятий должны справляться со сложностью, которая характерна для Industry 4.0 в различных измерениях, чтобы 
использовать возможности цифровых технологий для своих сайтов. При этом развитие управляемых служб промышленной безопасности может способствовать стабилизации промышленной системы.

Кроме того, цифровизация существенно расширила возможности обработки и анализа массива информации и знаний об окружающем мире («Больших данных» - «Big Data»).

Наконец, обработка и анализ Big Data были бы невозможны без экспоненциального роста в области программного обеспечения, в том числе и собственно в технологических процессах.

Как уже указывалось, прорыв в информационных технологиях стал возможен благодаря развитию полупроводниковой техники, начиная со второй половины XX века. Дальнейшая минимизация больших интегральных схем и минимизация элементной базы электронной техники привели к тому, что компьютеры стали не просто достоянием государственных структур и крупных корпораций, а со временем появились в каждом домохозяйстве. То есть со временем пользователями различных видов персональной электронно-вычислительной техники стал практически каждый житель нашей планеты.

Свыше 60 лет назад канадский философ Маршал Маклюэн ввел в социально-философский тезаурус понятие «глобальная деревня», под которым подразумевал систему мгновенной взаимосвязи индивидов на всём земном шаре в результате наступления эффекта имплозии - «сжатия» глобального мира [7]. Предвидения осуществились благодаря изобретению сотовой связи и её коммерческой и технологической доступности.

Более того, развитие средств коммуникации и сотовой связи создало предпосылки для того чтобы из простых средств коммуникации устройство взаимосвязи превратились в полноценные карманные компьютеры, начиненные сложным программным обеспечением. Это обеспечение позволяет переводить, коммуницировать, общаться по видеосвязи, проводить сложные вычисления, имея под рукой лишь смартфон, который, таким образом, является больше, чем просто телефоном.

Вместе с тем, еще Г.М. Маклюэн также обратил внимание на то, что усложнение современных технологий, в том числе и в области коммуникации сопрягает существование человека с различными 
новыми рисками, опасностями и угрозами. Так, генезис и активное использование новых технологий существенным образом трансформирует сенсорное восприятие индивидом среды, окружающей его, в результате чего происходит подрыв его самоидентификации [1]. Уже в наши дни мы видим, что, к сожалению, процессы цифровизации лишь усугубили данную тенденцию нарастания рисков [6]. Эти риски и угрозы является продуктом не только новых промышленных и социальных технологий [8]. Иначе говоря, в постиндустриальном обществе технологический прорыв, связанный с процессами информатизации и цифровизации, приводит к появлению новых рисков для всех субъектов общества.

В современном постсовременном, постиндустриальном обществе технологии играют ведущую роль в создании социокультурного ландшафта. При этом процессы информатизации, цифровизации и медиатизации не только переформируют элементы, институты и подсистемы современной социальной структуры, но и фактически приводят к появлению и использованию новых алгоритмов их функционирования. Кроме того, возрастающая координация элементов современной социальной системы привела к оформлению четких контуров такого неоднозначного по своим эффектам явления как «глобализация». Поэтому необходимым является проведение исследования негативных и позитивных тенденций и сопутствующих рисков процессов информатизации в современных условиях глобализации и цифровизации жизнедеятельности индивидов с учетом контроля за их деятельностью со стороны социальных структур.

\section{Список литературы}

1. Давыдов Д.А. Концепция постматериализма Роналда Инглхарта в критической перспективе // Научный ежегодник Института философии и права Уральского отделения Российской академии наук. 2018. Т. 18. Вып. 3. С. 86-102.

2. Пелевин С.И. Современное общество в контексте технологических процессов: социально-философский анализ // Kant. 2019. № 1 (30). C. 213-217. 
3. Carlos M. Roos Mediatization Theory: What is in It for the Philosophy of Communication? On Stig Hjarvards The Mediatization of Culture and Society // Empedocles: European Journal for the Philosophy of Communication. 2015. V. 6 No 1, pp. 91-103.

4. Hansson S. O. Ethical Criteria of Risk Acceptance // Erkenntnis. 2003. V. 59. No 3, pp. 291-309. doi:10.1023/A:1026005915919

5. Inglehart R.F. The Silent Revolution: Changing Values and Political Styles Among Western Publics. Princeton : Princeton Univ. Press, 1977. 496 p.

6. Jacobson J., Gruzd A. Cybervetting Job Applicants on Social Media: The New Normal? // Ethics and Information Technology. 2020. V. 22. No 2, pp. 175-195.

7. Jansen Ch., Jeschke S. Mitigating Risks of Digitalization Through Managed Industrial Security Services // AI and Society. 2018. V. 33 No 2, pp. 163-173.

8. McLuhan M., Fiore Q. War and Peace in the Global Village. N.Y.: Bantam, 1968. 192 р. - русский перевод: Маклюэн М., Фиоре К. Война и мир в глобальной деревне. М.: АСТ, Астрель, 2012. 226 с.

9. McLuhan M., The Gutenberg Galaxy: The Making of Typographic Man. Toronto: University of Toronto Press, 1962. 293 p. - русский перевод: Маклюэн М. Галактика Гутенберга. Становление человека печатающего. 2-е изд. М.: Академический Проект, Гаудеамус, 2013. 496 с.

10. Vodenko K.V., Cherkesova E.Y., Shvachkina L.A., Fateeva S.V., Erosheva I.Y. The Specifics of the Socio-Cultural Determination of the Current Economic Activity // International Journal of Economics and Financial Issues. 2016. V. 6. No S1, pp. 206-210.

\section{References}

1. Davydov D.A. Nauchnyj ezhegodnik Instituta filosofii i prava Ural'skogo otdeleniya Rossijskoj akademii nauk. 2018. V. 18. Issue 3, pp. 86-102.

2. Pelevin S.I. Kant. 2019. № 1 (30), pp. 213-217.

3. Carlos M. Roos Mediatization Theory: What is in It for the Philosophy of Communication? On Stig Hjarvards the Mediatization of Culture and Society. Empedocles: European Journal for the Philosophy of Communication. 2015. V. 6, No 1, pp. 91-103. 
4. Hansson S. O. Ethical Criteria of Risk Acceptance. Erkenntnis. 2003. V. 59. No 3, pp. 291-309. doi:10.1023/A:1026005915919

5. Inglehart R.F. The Silent Revolution: Changing Values and Political Styles Among Western Publics. Princeton: Princeton Univ. Press, 1977. 496 p.

6. Jacobson J., Gruzd A. Cybervetting Job Applicants on Social Media: The New Normal? Ethics and Information Technology. 2020. V. 22. No 2, pp. 175-195.

7. Jansen Ch., Jeschke S. Mitigating Risks of Digitalization Through Managed Industrial Security Services. AI and Society. 2018. V. 33 No 2, pp. 163-173.

8. McLuhan M., Fiore Q. War and Peace in the Global Village. N.Y.: Bantam, 1968. $192 \mathrm{p}$.

9. McLuhan M. The Gutenberg Galaxy: The Making of Typographic Man. Toronto: University of Toronto Press, 1962. 293 p.

10. Vodenko K.V., Cherkesova E.Y., Shvachkina L.A., Fateeva S.V., Erosheva I.Y. The Specifics of the Socio-Cultural Determination of The Current Economic Activity. International Journal of Economics and Financial Issues. 2016. V. 6. No S1, pp. 206-210.

\section{ДАННЫЕ ОБ АВТОРЕ}

Пелевин Сергей Игоревич, кандидат политических наук, доцент кафедры философии, права и социально-гуманитарных наук ФГБОУ ВО «Армавирский государственный педагогический университет»

ул. Обороны, 30, Новокубанск, Краснодарский край, 352240, Российская Федераичя pelevin17@gmail.com

\section{DATA ABOUT THE AUTHOR}

Pelevin Sergei Igorevich, Candidate of Political Sciences, Associate Professor of the Department of Philosophy, Law and Social Sciences and Humanities Armavir State Pedagogical University

30, Oborony Str., Novokubansk, Krasnodar Territory, 352240, Russian Federation pelevin17@gmail.com 